\title{
DÊIXIS: DA VISÃO CLÁSSICA À PERSPECTIVA DA REFERENCIAÇÃO
}

\section{DEIXIS: FROM THE CLASSICAL VISION TO THE REFERENCE PERSPECTIVE}

\author{
Evando Luiz e Silva Soares da Rocha* \\ Ailma do Nascimento Silva**
}

Resumo: Desde as discussões clássicas sobre os estudos da linguagem humana até o contexto da concepção de Referenciação em Linguística de Texto, a função de "apontar" conferida aos dêiticos desperta investigações sobre o que de fato é dêixis. Objetivamos discutir definições de dêixis no âmbito dos estudos da linguagem humana consignando-a a dinâmica da comunicação e pretensões dos actantes. Nesse intento, a partir de uma pesquisa bibliográfica, debruçamo-nos sobre trabalhos fundamentados na concepção de Referenciação processo cognitivo e sociodiscursivo, donde destacamos as contribuições de autores, como: Cavalcante (2000, 2012), Cruz (2011), Fiorin (2011), Ciulla e Martins (2017) Ciulla (2018), Leal (2015), dentre outros autores, que retomam, discutem e aprofundam noções sobre dêixis. A pesquisa revelounos que a relação de deiticidade ou função dêitica é estabelecida na e pela dinâmica da interação. Esperamos contribuir para a ampliação e entendimento das noções definidoras de dêixis nos estudos contemporâneos da linguagem.

Palavras-chave: Referência; Referenciação; Dêixis.

Aвstract: From the classic discussions about the studies of human language to the context of the concept of Referencing in Text Linguistics, the function of "pointing" conferred to the deictics raises investigations about what in fact deixis is. We aim to discuss definitions of deixis within the scope of human language studies, consigning it to the dynamics of communication and the actors' pretensions. In this attempt, from a bibliographical research, we focus on works based on the concept of Referencing cognitive and sociodiscursive process, from which we highlight the contributions of authors, such as: Cavalcante (2000, 2012), Cruz (2011), Fiorin (2011), Ciulla and

\footnotetext{
"Graduado em Letras Português e mestre pelo Programa de Mestrado Acadêmico em Letras da Universidade Estadual do Piauí (Uespi). Professor efetivo de Língua Portuguesa da Unidade Integrada Vicente Pereira dos Santos (SEMED), Parnarama-MA. E-mail: evevinho@gmail.com.

** Professora Doutora, exerce a função de Pró-reitora de Pesquisa e Pós-Graduação. É professora permanente do Programa de Mestrado Profissional em Letras (PROFLETRAS/UESPI) e Mestrado Acadêmico em Letras. E-mail: ailmanascimento@yahoo.com.br.
} 
Martins (2017) Ciulla (2018), Leal (2015), among other authors, who resume, discuss and deepen notions about deixis. The research has revealed that the relationship of deixs or deixis function is established in and by the dynamics of the interaction. We hope to contribute to the expansion and understanding of the notions that define deixis in contemporary language studies.

KEYwords: Reference; Referencing; Deixis.

\section{INTRODUÇÃo}

A definição de dêixis amplamente discutida na Linguística de Texto, doravante LT, alinhada ao viés cognitivo da concepção de Referenciação, emerge das diversas contribuições aventadas desde as discussões filosóficas clássicas sobre o estudo da linguagem, bem como das abordagens contemporâneas. Neste contexto, assumir uma definição mais ampla de dêixis requer adentrar no universo de estudos e discussões assentadas nos estudos da Referência clássica e da perspectiva da Referenciação, conciliando as posições atinentes ao fenômeno sob um prisma textual discursivo.

O que nos mobiliza na construção deste trabalho é a compreensão de que, apesar de representar um campo de estudo tradicional e consolidado, no contexto atual das pesquisas sobre dêixis em LT, há tanto inclinações para as definições, quanto para as rediscussões do quadro classificatório. Encaminhamos nossa posição aqui, no sentido de dialogar com as definições de dêixis, para, de acordo com os pressupostos teóricos, discutirmos a abrangência dessas definições em contextos comunicativos. Neste trabalho, assumimos como visão clássica de dêixis as abordagens que a descrevem pela noção de orientar, apontar. Assim, visamos estender o conceito de dêixis para além das realizações ostensivas, tradicionalmente caracterizadas pelo léxico e pelo emprego gramatical de expressões indiciais.

A visão inicial de dêixis instaurada nos estudos clássicos da linguagem sugere noções de apontar, mostrar, indicar, conforme as coordenadas de pessoa, tempo e lugar. E, entendendo que, na Referenciação, os dêiticos comportam diferentes olhares sobre suas manifestações nas situações comunicativas, propomos-nos a discutir a extensão dos conceitos considerando a dinâmica da comunicação e da negociação dos sentidos, englobando, também, os dêiticos de memória, textual e social.

Neste trabalho, evidenciar definições de dêixis representa uma retomada das características elementares de termos indiciais e de ostensão, que, mesmo antes da concepção de Referenciação postulada por Mondada e Dubois (2003 [1995]), já creditava em seu favor a relação linguagem e contexto. Por isso, recorremos aos autores que não só discutem esta noção, mas ampliam a percepção sobre os dêiticos, como Fonseca (1996), Cavalcante (2000, 2012), Ciulla (2002, 2018), Martins (2019), dentre outros que também retomam o tema e o aprofundam com propriedade. 
Na referência clássica, a compreensão de dêixis, mesmo relacionando a deiticidade à situação de comunicação, passava pela ideia de fixação de conceitos delimitados, principalmente, pelos usos e escolhas de pronomes e advérbios. Optamos por uma discussão ampla que envolve noções de Referência caracterizada pelos sentidos dados a priori, pré-existentes e de Referenciação que comporta os precessos de negociação para se construir sentidos na e pela interação.

Assumimos, portanto, o lugar de uma pesquisa bibliográfica centrada nos estudos da linguagem e nas abordagens das expressões linguísticas do ponto de vista da interação. Entendemos que a referenciação dêitica, além de evidenciar importantes facetas das coordenadas de pessoa, tempo e lugar, como a referência clássica concebia, revela também os aspectos sociodiscursivos da linguagem humana contemplados na e pela concepção de Referenciação.

Neste intento, organizamos este trabalho numa seção de fundamentação dividida em dois subtópicos. No primeiro, apresentamos as definições mais consistentes do fenômeno a partir de abordagens oriundas de diferentes frentes teóricas. No segundo, espelhamos essas definições em contextos comunicativos em que a dêixis é recorrente. Em seguida, trazemos as considerações finais, em que reafirmamos a importância das discussões apresentadas sobre o tema.

\section{DêIXIS E REFERENCIAÇÃo}

No estágio atual dos estudos em LT sobre a construção da referência que visamos trazer à tona nesse trabalho, assumimos que as expressões que representam as dêixis têm lugar privilegiado na relação linguagem e contexto (FONSECA, 1996). E, mais do que isso, os dêiticos assumem papéis importantes no campo da Referenciação enquanto processo congnitivo.

Assim, a partir das teorizações e postulados dispostos nos estudos da linguagem, tratamos a definição de dêixis sob o ponto de vista da Referenciação processo sociocognitivo e discursivo, cujo entendimento emerge da relação de construção dos sentidos na situação de interação em que ocorre negociação entre os participantes da comunicação (MONDADA; DUBOIS, 2003 [1995]). Da mesma forma, abordamos diferentes posições teóricas assentadas no bojo dos estudos da linguagem que situam o fenômeno de dêixis na relação língua e mundo. Consideramos basilares em nossa proposta de discussão e revisão da literatura as contribuições de Cavalcante (2000, 2012), Leal (2015), Ciulla e Martins (2017) e Ciulla (2018), dentre outras.

\section{DEFININDO DÊIXIS}

Dêixis é tema discutido em várias frentes teóricas, fazendo-se objeto de áreas como a Filosofia da Linguagem, da Psicologia, da Antropologia e da Linguística, dentre outras. Aqui, para efeito das discussões a que nos propomos, abordamos o tema sob o olhar da Linguística 
Textual. Entretanto, isso não nos impede de comungar de ideias e visões estabelecidas noutros campos de estudos. Inclusive, definir dêixis numa ou noutra perspectiva supõe aproximar-se de constructos interdisciplinares.

No contexto da referência clássica, em que se considera que os sentidos são dados e conhecidos, o conceito de dêixis relaciona determinados constituintes linguísticos ao processamento da comunicação. De acordo com Fonseca (1996, p. 1, grifos da autora), "a dêixis constitui o modo como está gramaticalizada a inseparabilidade entre a linguagem e o contexto". Assim, de acordo com os estudos clássicos, os pronomes e advérbios, pelos seus aspectos de ostensão e de apontar para, revestem-se de deiticidade e ligam-se à situação de enunciação.

Nesse sentido, é consenso entre os estudiosos que as contribuições sobre o fenômeno das dêixis que emanam de abordagens interdisciplinares que surgiram de uma agenda de estudos influenciada pela Linguística. Assim sendo, "de um conceito mais restrito de dêixis como mostração vai-se passando a um outro, mais amplo, de dêixis como referenciação" (FONSECA, 1996, p. 2, grifo da autora).

Concebida dessa forma, a dêixis inscrita numa determinada situação de comunicação aponta para elementos do contexto. Embora não seja nosso escopo aqui, neste ponto, a noção de dêixis diferencia-se da de anáfora, pois, esta remete aos referentes do cotexto e aquela a referentes da situação comunicativa.

A deiticidade é externa, portanto, é percebida quando a enunciação é engatilhada para demarcar o referente e não os significados. No cenário mais atual, tendo por base a concepção de Referenciação cognitiva, a noção de um dêitico é atrelada à ideia de renovação e atualização dos referentes e, considerada como tal, do ponto de vista da situação enunciativa, envolve: contexto, negociação e conhecimentos de mundo compartilhados.

Cavalcante (2000) explicita a dêixis considerando-a na situação de comunicação como ponto de partida, mas sem um sentido constituído, estanque, pois, este constrói e reconstrói-se no contexto em que é enunciado e reelaborado a depender da interação. Visto dessa maneira, a manifestação de dêixis foge à lexicalização de ocorrências ou representações marcadas na língua, pois, a enunciação é renovada constantemente pelos participantes como que reelaborando a realidade. Assim, entendemos que o fenômeno extrapola a relação eu/tu do contexto enunciativo e espraia-se na referencialidade da língua.

Cabe-nos ressaltar ainda que, pela noção de referência clássica, as visões sobre dêixis discriminam as categorias de pessoa, de tempo e de espaço. Neste sentido, as abordagens de estudos da linguagem, a priori, associavam a ostensão ao parâmetro de gramaticalidade e objetividade da linguagem num percurso considerado simplista. Aqui, entendemos que a definição de dêixis nos estudos clássicos é suscetível à relação linguagem e contexto e, a partir da ostensão ou vinculação do sujeito enunciador na situação comunicativa, manifesta a característica de subjetividade. 
As questões pontuais sobre dêixis nos levam a compreendê-la como resultado da relação que se estabelece entre uma expressão linguística e um componente da situação enunciativa. Na ciência da linguagem, segundo Cavalcante (2000, p. 27), "é com Bühler (1982) que o estudo de dêixis passa a ser encarado como um conceito chave para entender a linguagem". Inclusive, é pela natureza dos dêiticos que se creditam diferenças entre a linguagem humana e as linguagens artificiais. Nesse intento, segundo a autora, o teórico serviu-se de bases da Psicologia para anunciar as noções de campo (grifo nosso), que demonstrou através de campo simbólico e campo mostrativo, e é neste último que empreende e aprofunda a teorização sobre dêixis.

No campo da linguagem e com inclinações que contribuem tanto para as perspectivas definidoras quanto classificatórias, também citado pela autora, o trabalho de Benveniste (1988), mesmo não tendo a dêixis como objeto, contribuiu para desvelar o eu e o tu da enunciação em relação ao que é ou não dêitico. Dessa forma, reconhecemos que são numerosos os aportes teóricos que contribuem para o refinamento dos estudos dos dêiticos na contemporaneidade das abordagens linguísticas.

Inclusive, Cavalcante (2000), ao reconhecer a importância do sujeito enunciador e da consideração do caráter de subjetividade, inclina-se a noção de dêixis como expressão "símbolo-índice", aproximando-se da visão posta em Lahud (1979). Cabe ressaltar que, enquanto símbolo, o sentido/significado da expressão é determinado sob a égide das convenções, abrindo precedentes para relacionar os sentidos de um dêitico a certas incursões contextuais. Nisso, é preciso salientar também que, citando Bühler (1982) e Benveniste (1988), Cavalcante (2000) considera que os aportes teóricos sobre a natureza ostensiva dos dêiticos são díspares.

Porquanto, não buscamos encontrar afiliações teóricas entre os autores, mas apenas demonstrar que imprimiram instâncias teóricas relevantes que nos ajudam a compreender esse fenômeno da linguagem. Dessa forma, no campo da Linguística, as contribuições de Cavalcante (2000), ao retomar os postulados de Benveniste (1988), evidenciam que, embora não seja diretamente o seu objeto, a dêixis é recorrente e profícua pela visão de língua/linguagem e pela descrição de sujeito na relação eu/tu/você na situação enunciativa.

Nesse aspecto, ao discutirmos definições de dêixis e sabendo que pronomes e advérbios são apontados como protótipos do fenômeno, alcançamos um entrecruzamento em que se tornam convergentes as posições sobre ser a dêixis uma instância natural da linguagem humana relacionar-se com o mundo exterior. Assim, é preciso demarcar o que de fato é dêixis, considerando o que está explícito ou implícito na situação comunicativa e o que eventualmente assume a face de um dêitico. A esse respeito, um esclarecimento pontual é que:

Convém deixar bem claro que o que se tem chamado de "função dêitica" e o que tradicionalmente se conhece por "dêitico", ainda que sejam noções convergentes, não mantém entre si uma correspondência necessariamente recíproca. A função dêitica se efetiva na própria remissão, 
por seu papel ostensivo; ela promove a localização do objeto no universo do discurso criado pelo texto. E óbvio, pois, que um dêitico exerce obrigatoriamente uma função dêitica. Mas o inverso não se verifica, pois nem toda forma que desempenha função dêitica é, necessariamente, um dêitico, como as expressões referenciais anafóricas [...] (CAVALCANTE, 2000, p. 63).

Consideramos significativas essas acepções e definições sobre os dêiticos, sinalizando que a noção de referência não é fixa, como apregoa a concepção de Referenciação socio cognitiva que veio posteriormente ser acolhida no campo da Linguística de acordo com os postulados de Mondada e Dubois (2003 [1995]). A seguir, as discussões encaminham posições sobre a relação linguagem e situação comunicativa, por isso, servimo-nos de exemplos recortados de contextos reais de usos da língua.

\section{DÊIXIS E OS ELOS DISCURSIVOS}

Assim, não mais sob o viés da referência, a dêixis, nesse contexto, não se prende aos sentidos ou coordenadas tradicionais definidas pela noção de "apontar para". Mas, como forma de referir o mundo, segundo Apothéloz (2003, p. 68, grifos do autor), "a característica definidora dos dêiticos é que seu modo de referência se apoia num referencial e não nos significados".

Ao tratar da referenciação dêitica, Sousa (2005) destaca a manutenção da definição clássica, que manifesta a função de mostrar, apontar para. Nesse contexto, para exemplificar o que vimos discutindo, segue o exemplo.

(1) A família está cheia de problemas; você quer resolver, mas não pode fazer nada (SOUSA, 2005, p. 117, grifo da autora).

Ao enunciar tal sentença, a autora chama a atenção para a relação eu/tu/você da enunciação, discutindo sobre quem ou a que o pronome se refere, pois, pretende evidenciar que não se trata de um você específico, propriamente a segunda pessoa do discurso, no caso, o receptor da mensagem, mas um você genérico que se reconhece na cena enunciativa. No tocante à dubiedade em se definir a expressão como dêitica ou não, e com base na sentença, reconhecemos que há, na expressão, o gesto de apontar para um referente localizável na situação enunciativa.

Para nós, o termo "você" desempenha a função dêitica porque aponta, designa um enunciador participante da interação cuja identidade é construída na origem da enunciação. Seja por integrar o grupo familiar e ser não o "você" que ouve ou recebe a mensagem, mas um "você" com lugar de fala na cena comunicativa seja pela subjetividade do contexto em que o dêitico aponta para um referente e não para um significado subjacente à lexicalização de uma expressão linguística. 
Para ampliar a concepção de dêixis, a partir do percurso da definição clássica do fenômeno, reportamo-nos às considerações de Cruz (2011, p. 24), "importado da língua grega, o termo dêixis, etimologicamente, tem o sentido de apontar, mostrar, indicar". Entendemos que a função ou gesto de apontar é uma recorrência da e na linguagem, no âmbito da dêixis a que o autor se refere, é a expressão que liga o linguístico ao contexto de enunciação e que, neste mostrar, apontar criam-se relações pessoais, espaciais e temporais, entre enunciadores e interlocutores, isto é, a dêixis instância da enunciação estabelece elos discursivos entre a linguagem e o contexto.

O que se admite a partir desses postulados é que a dêixis se define pela consignação de um "eu/tu/você" que enuncia, de onde enuncia e quando enuncia. Isto é, a noção de dêixis em referenciação processo, parte da relação (eu/tu, aqui e agora) que determina as coordenadas de pessoa, tempo e lugar da enunciação. A propósito, segundo Fiorin (2011), os dêiticos só se tornam totalmente entendidos numa dada situação enunciativa em que se reconhece o ponto de partida do ato de enunciação. Vejamos o caso dado no exemplo a seguir:

(2) No próximo sábado o Fortaleza jogará com o Palmeiras (SOUSA, 2005, p. 121, grifos da autora).

Conforme as considerações de Fiorin (2011), enquadrar uma expressão enquanto dêitica exige o reconhecimento da situação de enunciação. Neste exemplo, ao enunciar "no próximo sábado", de imediato creditamos a ideia de um dêitico temporal e, de fato o é, pois, quando se diz dessa forma, os coenunciadores associam via discurso que se está referindo ao sábado mais próximo do dia em que a fala ocorre. Para nós, fica evidente que uma expressão lexical que indica, por exemplo, pessoas do discurso, ou refere-se a tempos e lugares, de fato só constitui dêixis numa situação comunicativa em que se reconheça o eu, o aqui e o agora da enunciação.

Nessa mesma linha, segundo Cavalcante, Custódio Filho e Brito (2014, p. 156), dêixis "são expressões referenciais que criam um vínculo entre o enunciado e a situação enunciativa estabelecida pelos interlocutores no momento da enunciação". Neste sentido, compreendemos que os dêiticos, ao integrarem a situação comunicativa, além da característica de ostensão, evidenciam relações no discurso instaurado, denunciando posições do enunciador e dos coenunciadores no tempo e no espaço, além de acionarem conhecimentos que compartilham socialmente.

Na mesma perspectiva, Leal (2015) também se refere aos dêiticos como formas de referenciação. Para a autora, a noção clássica de dêixis numa dimensão definidora e classificatória deve-se ao trabalho precursor de Bühler (1982). No paradigma da Referenciação, parece-nos razoável dizer que o papel dos dêiticos vai além das coordenadas de pessoa, tempo e lugar, atribuídas, principalmente, aos pronomes e advérbios gramaticalizados no ato enunciativo. Dessa forma, com base na concepção de Referenciação, consideramos que é na dinâmica da interação comunicativa que se dá a referência dêitica (MONDADA; DUBOIS, 2003 [1995]). 
Com origens na Filosofia da Linguagem, na Psicologia e na Linguística, bem como em outras áreas, as lacunas quanto ao objetivo de definir dêixis remetem-nos tanto à percepção dos estudos clássicos da linguagem, quanto às discussões contemporâneas no campo da referenciação enquanto processo sociocognitivo e discursivo. Leal (2015) considera que a compreensão dos dêiticos depende de conhecimentos prévios, considerando contexto e sujeitos desse espaço.

Para Ciulla e Martins (2017, p. 4), "o referente de um dêitico é um vazio que pode ser ocupado por todos os "particulares" capazes de estabelecer com o ato de fala a relação significada pelo dêitico em questão". Assim, acompanhando a inscrição de um referente na cena enunciativa, entendemos, conforme a assertiva das autoras, que se trata de um vazio no campo da referência, uma vez que os sentidos estão na subjacência do signo ou nas subjetividades do contexto, logo o preenchimento do vazio emana das coordenadas do discurso. Havendo, pois, um dêitico, há também uma linha da gramaticalidade ao contexto, e, nisso, estão inscritos os referentes. Senão, vejamos o exemplo (03) criado para fins desta pesquisa, dados do pesquisador (2019):

(3) O hotel fica para lá.

Concebemos, em consonância com a autora, a ideia de que a dêixis é por definição um indicial, às vezes, marcado no léxico, dado a priori pelas representações e simbologia da linguagem. É, pois, a dêixis como a expressão destacada na sentença (03) uma expressão que permite reconstruir o ato enunciativo para de fato se perceber um referente. Dessa forma, discutir a noção de vazio ajuda-nos a entender que o conhecimento alcançado no discurso aliado ao gesto de apontar para constroem a referência e definem a deiticidade de uma expressão. Então, considerar que o termo "lá" é uma dêixis no exemplo (03) supõe dominar a relação linguagem e contexto, percebendo de onde emerge a enunciação, e assumir que o indicial aponta para um lugar conhecido ou construído a partir dos conhecimentos da situação compartilhados pelos interactantes.

Atualmente, conforme Ciulla (2018, p. 2), "nota-se uma preocupação menor em definir o fenômeno e maior em observar tipos e funções no discurso". Diante disso, concordamos com a autora e, resumindo nossas discussões, a evocamos para salientar a recorrência a duas vertentes de estudos de dêixis, uma ligada ao caráter de ostensão herdado da definição grega e outra mais direcionada aos aspectos interativos sociodiscursivos da linguagem. Entretanto, a ostensão é a característica que marca as duas vertentes.

Assim, Ciulla (2018, p. 3, grifo da autora) se manifesta:

Sob essa perspectiva, o "apontar" para referentes torna-se a principal característica e, assim, na maior parte das tipologias, as abordagens não são excludentes, isto é, consideram-se como dêixis, tanto os casos de apontamento gestual e de saliência da situação discursiva, quanto os 
que dependem de uma remissão ao eu explicitada somente na língua, independentemente de indicações e sinais realizadas durante o ato comunicativo.

Como viemos discutindo, a dêixis no contexto da Referenciação é atravessada pela dinâmica das interações comunicativas, bem como se constrói em função das atividades sociocognitivas e discursivas. Ao discutir o fenômeno de dêixis, Martins (2019) revela que as coordenadas de tempo, pessoa e lugar são definidas e atualizadas na interação pelo enunciador. A propósito, a autora revisita a definição clássica e o lugar de dêixis na Referenciação como processo cognitivo e discursivo, para sustentar que a dêixis não é um indicial de ocorrência puramente cotextual, mas elos referenciais que apontam do ponto de vista localizável do enunciador no ato enunciativo.

Então, as definições construídas sobre o fenômeno da dêixis não abandonam a função dada no bojo da referência clássica que atribui aos dêiticos a função de apontar para, segundo as coordenadas de pessoa, tempo e lugar. Além disso, mantém a percepção de inseparabilidade entre a linguagem e contexto. Entretanto, assumir uma ocorrência dêitica, para nós, requer entender o eu/aqui/agora da enunciação postos em evidência pela interação do enunciador e coenunciadores via linguagem e contexto.

Mais do que isso, o dêitico define-se pela noção discursiva de demarcar socio cognitivamente entidades do cotexto. Assim, no paradigma das abordagens contemporâneas, além de construir ampliações e atualizações para o quadro de definições e classificatório de dêixis, os estudos redimensionam os olhares sobre a ocorrência do fenômeno sob o viés sociocognitivo e discursivo.

Assumimos, nesta discussão, que a percepção de que o dêitico muda, mas a coisa representada no mundo não, já não tem razão de ser nos estudos firmados no lastro da concepção de Referenciação, principalmente incorporando as categorias dos dêiticos discursivos que ampliam a relação de subjetividade linguagem e contexto. Nessa concepção, dentre outras coisas, consideramos a dinâmica em que os referentes são apontados na situação discursiva.

Com bases nos estudos assentados no campo referência clássica dispostos na LT, falamos inicialmente em dêixis de pessoa, espaço e tempo. Segundo Fonseca (1996), essa tipologia deriva das coordenadas da enunciação eu/tu, aqui e agora postuladas a partir do gesto ou função de apontar para. Aqui, ao mencionarmos classificação tradicional, estamos acompanhando a designação usada por Cavalcante (2000) para os casos que abrangem os dêiticos pessoais, espaciais e temporais. Depois, tornamos evidentes as discussões sobre as classificações de dêixis social, textual e de memória cujas definições as conectam a referentes, situações ou espaços da enunciação.

Em trabalho posterior, ao abordar as dêixis e anáforas, Ciulla (2002) sugere um quadro recategorizador em que situa os dêiticos de pessoa, lugar, tempo e memória no grupo das 
expressões referenciais que não fazem remissão ao cotexto e os dêiticos discursivos, social e textual no grupo dos que remetem a referentes na superfície textual. O olhar sobre essas posições requer domínio tanto da noção de apontar para referentes quanto a compreensão do processo de reconstrução da realidade.

Assim, tomemos como dêixis de pessoa o caso da expressão linguística destacada no trecho do poema Motivo, de Cecília Meireles:

(4) Eu canto porque o instante existe

e a minha vida está completa.

Não sou alegre nem sou triste:

sou poeta.

Disponível versão em: https://armazemdetexto.blogspot.com/2018/04/poema-viagem-motivo-cecilia-meireles.html.

A rigor, a expressão em destaque não é apenas um indicativo do "eu-lírico" que se manifesta poeticamente, do eu que diz "eu". É, na verdade, uma generalização que aponta para qualquer "eu" que, na enunciação, assuma ou compartilhe como coenunciador o ato enunciativo. Então, é um dêitico pessoal porque aponta para um referente que, na situação comunicativa, assume-se como tal e atualiza-se, renova-se e inscreve-se na referencialidade da língua.

Conforme Sousa (2005), Leal (2015) e Martins (2019), a dêixis pessoal traz, na sua conjuntura, as formas lexicais e a gramaticalidade dos pronomes pessoais. Entretanto, os autores chamam a atenção para o fato de que mais do que marcar pessoas do discurso, eles apontam para os enunciadores da relação eu/tu/você da enunciação, tornando a identidade do enunciador somente reconhecida se houver interação e compartilhamentos de conhecimentos na situação comunicativa. De acordo com Cruz (2011, p. 32), "a dêixis de pessoa é responsável pelo reconhecimento dos interactantes na enunciação". Nisso, entendemos conforme o autor que esta categoria, além de mostrar, apontar para os sujeitos, situa de fato quem é o "eu" que se assume na enunciação.

Sobre os dêiticos espaciais, traçamos um recorte sobre uma anedota retirada de repositório da internet, para exemplificar e discutirmos a sua realização enunciativa.

(5) Lápide

Aqui jaz tio Zé

Que acendeu um fósforo para ver se o tambor tinha gasolina... .... tinha.

Disponível versão em: https://www.osvigaristas.com.br/frases/aqui-jaz-o-tio-ze-que-acendeu-um-fosforo-paraver-se-o-tambor-tinha-gasolina-221497.html.

Segundo Cruz (2011, p. 35), "para sabermos a que local se referem os dêiticos de lugar, é necessário conhecer o ponto de origem do interlocutor". Nesse ponto, cabe a definição de 
locais específicos, uma vez que são próprios das interações, os movimentos sugeridos por determinados termos, os quais demarcam não só o aqui, mas também o ir e vir.

Ao focarmos no espaço da enunciação sugerido na anedota, deparamo-nos, inicialmente, com um "aqui" no papel de dêixis, visto que a referência de lugar, sem o conhecimento da situação comunicativa, é de fato um vazio, conforme Ciulla e Martins (2017), mas, se os interlocutores interagirem e seguirem as pistas do contexto da enunciação, esse vazio é preenchido e torna-se saliente do ponto de vista do enunciador.

Sobre os dêiticos temporais, as discussões encaminham-nos para uma relação proximal com a dêixis espacial, indicando que os lugares e os tempos da enunciação se imbricam na interação. Vejamos o exemplo (06), criado para fins desta pesquisa, dados do pesquisador (2019).

(06) Primeiro a obrigação, depois a diversão!

Como vemos na sentença dada, as expressões que se referem a tempo, geralmente gramaticalizados sob a forma de advérbios, para cumprirem a função dêitica, precisam situar os actantes no tempo do enunciador. Em (06), a expressão sublinhada é uma dêixis porque permite aos participantes construírem um tempo localizável do ponto de vista enunciativo. Logo, o termo "depois" não cumpre a finalidade de organizar a ordem dos eventos, mas é um momento inscrito na enunciação que situa o tempo de realização das ações.

Dessa forma, "os dêiticos temporais, ao serem utilizados na enunciação, tornam-se responsáveis por marcar temporalmente a referência com o fim de situar os falantes (CRUZ, 2011, p. 33)". Depreendemos dessa noção que os envolvidos numa interação podem não se inserir no mesmo tempo da enunciação e que é através da compreensão do elemento dêitico que a relação actantes/tempo torna-se efetiva para a comunicação. Conforme Leal (2015), os dêiticos temporais situam o momento ou ato de fala do enunciador.

De posse do conhecimento de que, tanto pronomes, quanto advérbios e até os verbos cumprem papéis de "apontar para" referentes na situação comunicativa, passamos a tecer considerações sobre as ocorrências dos dêiticos discursivos. Por seu turno, Cavalcante (2000) discute os dêiticos discursivos a partir dos estudos já assentados, considerando a noção de subjetividade e acrescentando-lhes o parâmetro da abrangência dos indiciais.

Em estudos posteriores, Cavalcante, Custódio Filho e Brito (2014) e Leal (2015), numa mesma afiliação teórica, rediscutem as categorias discursivas no plano da referenciação sociocognitiva. Nessa linha, os autores citam o trabalho de Fillmore (1984 [1977]) como um marco para a agenda de estudos que incluíram os dêiticos social de memória e de texto no âmbito da Linguística.

Consideramos a dêixis social como realização independente, e não como subgrupo das dêixis de pessoa, de maneira semelhante ao que postularam Ciulla e Martins (2017). Para a descrição dessa categoria, vejamos o exemplo (07), título de uma canção de Marisa Monte, 
(7) Ao mestre com carinho.

Disponível versão em: https://www.ouvirmusica.com.br/marisa-monte/ao-mestre-com-carinho/.

O emprego da expressão linguística "mestre", na frase, serve-nos ao propósito de tornar clara a categoria de dêixis social. Em (07), o termo destacado é de fato um dêitico e, na interação, manifesta-se como forma afetuosa, respeitosa, um vínculo entre os actantes. "Mestre", nesse caso, não constrói uma visão superior do sujeito, mas agrega valor a quem se está referindo, assim, denuncia uma forma de como o enunciador trata um interlocutor ou um participante da interação. Além disso, supõe-se que seja um sujeito localizável na situação enunciada. É preciso entender, conforme Cavalcante (2012), Cavalcante, Custódio Filho e Brito (2014), que os sentidos são negociados pelos interlocutores na interação.

Nesse sentido, a expressão "mestre" poderia figurar apenas como uma marcação categórica de predicar quaisquer indivíduos sem estabelecer no cotexto qualquer ligação entre quem enuncia e para quem enuncia. A dêixis social é, segundo Leal (2015, p. 122), "um mecanismo de referenciação que leva em conta o discurso, quanto ao que ele reflete, estabelece ou é determinado por certas realidades da situação social em que o ato de fala ocorre". Além disso, a autora especifica que a relação entre dêixis social e pessoal é que as duas apontam para os interlocutores. Conforme Ciulla e Martins (2017) e Martins (2019), a dêixis social atua em relação à superfície cotextual.

Vejamos, no exemplo (08), a ocorrência de um dêitico textual, cuja especificidade na referenciação é dada pela consideração da relação sociocognitiva e discursiva de construção de sentidos. Assim, ao enunciar uma sentença como a do exemplo (08), disposta em Cavalcante (2012, p. 133, grifo da autora).

(08) O melhor emprego que Lula arranjou foi o de operário numa metalúrgica, onde se fabricam carros. Foi lá que ele começou a se destacar.

No exemplo dado, já analisado pela autora, o enunciador dirige a interlocução para uma porção localizável do cotexto. Mesmo em que, em suas análises, descreva a hibridização dêixis/anáfora, fica evidente que o termo "lá" aponta, a partir do discurso, para uma parte localizada no cotexto. Dessa forma, a noção de dêixis textual que discriminamos aqui sinaliza uma atualização do termo que fora anteriormente designado como dêixis discursiva. Para Cavalcante, Custódio Filho e Brito (2014), dêixis textual define-se pelas proposições de marcar ou identificar locais específicos na enunciação. E, ainda, segundo os autores, dêixis textual é uma estratégia discursiva que funciona dentro da situação comunicativa e aponta para partes ou porções textuais.

Em suas considerações sobre a dêixis textual, Leal (2015) credita seu engendramento ao trabalho de Fillmore (1984 [1977]). Entretanto, a autora não foca na descrição da dêixis textual pura, independente, senão, correlata ao processo anafórico, como também o fizera Cavalcante 
(2000), cujas discussões são retomadas por Ciulla e Martins (2017), que ressaltam o caráter subjetivo e híbrido desse tipo dêitico.

$\mathrm{Na}$ exposição a seguir, temos a ocorrência da dêixis memorial, cuja descrição encerra nossas discussões no exemplo (09), criado para fins desta pesquisa, dados do pesquisador (2019).

(09) Chegou e saiu naquelas condições.

Na sentença (09), o enunciador conduz o interlocutor pela enunciação a ativar conhecimentos que, em tese, compartilharam em algum momento. Dessa maneira, "naquelas condições" evocam referentes que estão no espaço da memória dos interlocutores. Por isso, assumimos que a referida expressão desempenha a função de um dêitico memorial. Cavalcante, Custódio Filho e Brito (2014) consideram que se trata de uma referenciação in absentia, ao que o enunciador toma para si a ideia de que os interlocutores já tenham conhecimento sobre determinada situação, isto é, acredita que compartilham dos mesmos conhecimentos dispostos no ato enunciativo.

Conforme Leal (2015), a dêixis de memória revela a importância de se compreender as pistas que são dadas na superfície textual ou no contexto para a recuperação da referência. Neste caso, reconhecemos em conformidade com o exemplo exposto em (09), que não há um referente explícito, ocorre que o enunciador considera que as experiências partilhadas com os coenunciadores sejam suficientes para a compreensão global do que enuncia.

Ciulla e Martins (2017) atribuem a Apothéloz (2003) os construtos de dêixis de memória e consideram que esse tipo dêitico projeta os referentes no espaço memorialístico dos actantes. Para as autoras, a dêixis de memória caberia uma associação com os dêiticos espaciais, pois, "trata-se de uma transposição do eixo de coordenadas, do espaço da situação imediata, para um espaço imaginado na memória" (CIULLA; MARTINS, 2017, p. 8). Entendemos que não se trata de situar a memória como uma coordenada de espaço físico de fato, mas reconhecê-la como o espaço onde se funda a imaginação e de onde e para onde os sentidos podem ser compartilhados.

Nesse contexto, e pelas discussões que empreendemos, consideramos que os dêiticos estão mais relacionados aos aspectos sociodiscursivos, construídos, compartilhados e negociados pelos participantes da situação comunicativa do que a lexicalização de uma expressão ou sua natureza gramatical na língua. Logo, os modelos teóricos que vaticinam definições e classificações para o fenômeno não são excludentes, ao contrário, mesmo atravessados por diferentes visões sobre o objeto, alinham-se pela pertinência das contribuições alcançadas independentemente do campo em que foram construídas. 


\section{ConsideraçõEs finaIS}

Neste trabalho, propomo-nos a discutir diferentes abordagens sobre o fenômeno de dêixis, que há tempos direcionam olhares no escopo dos estudos da linguagem. O que traçamos como objetivo coaduna com a inquietude em relação às definições abstratas, sejam elas construídas a partir de investidas no campo da Linguística, sejam provenientes de outros campos do conhecimento. Em vista disso, tornamos páreas as definições e situações comunicativas revestidas de deiticidade.

Na verdade, não existem tantos conceitos ou definições para o fenômeno de dêixis ao dispor das mais variadas áreas de abordagens, muito menos as teorizações rompem com noções já consolidadas em função de uma nova perspectiva de estudo. Como vimos, a noção de dêixis vem dos estudos clássicos da linguagem e contemporaneamente alberga contribuições gestadas na Psicologia ou na Linguística. Dentre outras possibilidades, a função de apontar para referentes nas situações [co] contextuais é o que enceta a maioria dos estudos que visam descrever o fenômeno de dêixis.

Entretanto, a definição dada em uma área não necessariamente completa ou anula a definição construída em outra. Assim, a compreensão de dêixis no contexto dos estudos da referência clássica não foi sobreposta nem se sobrepõe às visões do mesmo fenômeno sob o olhar da concepção de Referenciação cognitiva em LT, por exemplo.

A complexidade dada em relação à Referenciação toma por base a interação, considerando as relações entre sujeitos, linguagem e contexto. Então, sob o enfoque da LT, a pertinência de abordagens sobre dêxis a partir de diferentes perspectivas teóricas fornece bases para ressignificar não só o ponto de partida, mas também o ponto de chegada da enunciação para designar de fato o que é dêitico na situação comunicativa. Assim, consideramos relevantes as contribuições desta pesquisa para os estudos sobre dêixis em Linguística de Texto.

Desta feita, os traços classificatórios de dêixis num viés textual discursivo não descaracterizam os postulados da referência clássica, pois, conforme discutimos, os elos discursivos atinentes a contextos socioculturais, conhecimentos partilhados e experiências influenciam na categorização dos dêiticos, precisando melhor a origem da enunciação e os dizeres dos actantes. Assim, embora permaneçam algumas imbricações ou hibridizações entre um tipo e outro, as classificações sevem-se de parâmetros discursivos para justificar determinada posição.

Dessa forma, defendemos a relevância dos dêiticos discursivos perante a linha tênue da classificação tradicional que trouxemos especificada e que se encontra consolidada desde as discussões clássicas dos estudos da linguagem, considerando que a relação de deiticidade ou função dêitica é estabelecida na e pela dinâmica da interação. Assim, a face dos dêiticos é construída e revelada conforme uma instância enunciativa. Por isso, lançamos um olhar investigativo sobre manifestações da língua para perceber o que torna ou autoriza um termo assumir-se como dêitico. 
Por isso, no contexto dos estudos atuais sobre dêixis, dependendo do ponto de vista da abordagem, o recorte sobre o objeto, apesar de centrado em determinadas categorizações, também permite avançar sobre a relação linguagem, sujeito e mundo. Dessa forma, visando trazer à tona aspectos atinentes à função de apontar para, bem como as características de ostensão, de indiciais e/ou da relação língua/linguagem contexto, discutimos o fenômeno de dêixis considerando a interação e a perspectiva de atualização, renovação dos referentes e reelaboração da realidade no ato comunicativo.

\section{REFERÊNCIAS}

APOTHÉLOZ, D. Rôle et fonctionnement de l'anaphore dans La dynamique textuelle. Tese (Doutorado em Linguística). Université de Neuchatel, 1995, p. 18-43. In: CAVALCANTE, M. M.; RODRIGUES, B. B.; CIULlA, A. (Org.). Referenciação. São Paulo: Contexto, 2003.

BENVENISTE, Émile. Problemas de linguística geral. 2. ed. Tradução de Maria G. Novak; Maria L. Neri; revisão do Prof. Isaac Nicolau Salum. Campinas: Pontes. 2V. 1988.

BÜHLER, Karl. The deictic field of language and deictic words. In: JARVELLA, R. J.; KLEIN, W. (Ed.) Speech, place and action: studies in deixis and related topics. New York: John Wiley and Sons, p. 9-30. 1982.

CAVALCANTE, Mônica Magalhães. Expressões indiciais em contextos de uso: por uma caracterização dos dêiticos discursivos. 2000. 218 f. - Tese (Doutorado em Linguística) Universidade Federal de Pernambuco, Programa de Pós-Graduação em Letras, Recife, 2000. http://www.letrasvernaculas.ufc.br/index.php/biblioteca/teses/31-biblioteca/teses/52-tesemonica-cavalcante. Acesso em: 5 out. 2018.

CAVALCANTE, Mônica Magalhães, CUSTÓDIO FILHO, Valdinar; BRITO, Mariza Angélica Paiva. Coerência, referenciação e ensino. São Paulo: Cortez Editora. 2014.

CAVALCANTE, Mônica Magalhães. Os sentidos do texto. São Paulo: Cortez, 2012.

CIULLA, Alena. Anáforas e dêixis: semelhanças e diferenças. Revista Anais / corrigido. pmd. Pesquisas em Linguística e Literatura: Descrição, Aplicação, Ensino. Disponível em: http:// www.gelne.com.br/arquivos/anais/gelne-2002/artigos/o1_teoria_e_analise_linguistica/ artigoo2.pdf. Acesso em: 10 dez. 2018.

CIULLA, Alena. Sobre a definição de dêixis a partir de "A natureza dos pronomes". Revista do Programa de Pós-Graduação em Letras da Universidade de Passo Fundo, v. 14, n. 3, p. 364379, set./dez. 2018. Disponível em: seer.upf.br/index.php/rd/article/download/8581/114114361/. Acesso em: 1 dez. 2018.

CIULLA, Alena; MARTINS, Mayara Arruda. Um estudo sobre classificação de tipos dêiticos. Rev. De Letras. n. 36- v. 2, jul./dez. - 2017. Disponível em: www.periódicos.ufc.br/index.Php/ reveletras. Acesso em: 15 jun. 2018. 
CRUZ, Carlos Eduardo Ferreira da. Mudança dêitica e persuasão: a organização dêitica do texto por alunos do $6^{\circ}$ ano na transformação do discurso informativo em persuasivo / Carlos Eduardo Ferreira da Cruz - Fortaleza, 2011. Disponível em: http://www.uece.br/posla/ dmdocuments/CarlosEduardoFerreiradaCruz.pdf. Acesso em: 2 dez. 2018.

FILLMORE, C. J. Lectures on deixis. California: CSLI Publications Stanford, [1984]1997. Disponível em: https://web.stanford.edu/group/cslipublications/cslipublications/ site/1575860066.shtml. Acesso em: 17 dez. 2018.

FIORIN, José Luiz. Pragmática. In: Introdução à Linguística II. Princípios de análise. José Luiz Fiorin, (Org.). 4. ed. $3^{\circ}$ reimpressão. São Paulo: Contexto, 2011.

FONSECA, Fernanda Irene. Deixis e pragmática linguística. 1996. Disponível em: http://www. area.dge.mec.pt/gramatica/deixisirene5.html. Acesso em: 10 dez. 2018.

LAHUD, Michel. A propósito da noção de dêixis. São Paulo: Ática, 1979.

LEAL, Abniza Pontes de Barros. 0 processo Referencial da dêixis: por uma proposta de recategorização. 2015. 293f. - Tese (Doutorado em Linguística). Universidade Federal do Ceará, Departamento de Letras Vernáculas, Programa de Pós-graduação em Linguística, Fortaleza (CE), 2015. Repositório Institucional UFC. Disponível em: www.repositorio.ufc.br /handle/ iufc/12571. Acesso em: 12 nov. 2018.

MARTINS, Mayara Arruda. A caracterização dos tipos de dêixis como processos referenciais. Dissertação (Mestrado em Linguística) - Universidade Federal do Ceará, Centro de Humanidades, Programa de Pós-Graduação em Linguística, Fortaleza, 2019. Disponível em: http://www.repositorio.ufc.br/handle/riufc/42634. Acesso em: 11 jul. 2019.

MONDADA, Lorenza; DUBOIS, Danièle. Construcion des objets de discours et catégorisation: une approchedes processos de référenciation. TRANEL (Travauxneuchaâtelois de linguistiqyue). 1995, 23 p. 273-302. In: CAVALCANTE, M. M.; RODRIGUES, B. B.; CIULLA, A. (Org.). Referenciação. São Paulo: Contexto, 2003 [1995].

SOUSA, Maria Margarete Fernandes de. A organização textual-discursiva dos anúncios de turismo no Ceará. Tese (Doutorado em Linguística), Universidade Federal de Pernambuco, 2005. Disponível em: http://www.letrasvernaculas.ufc.br/images/PDF/Teses/tese-margaretefernandes.pdf. Acesso em: 12 maio de 2020.

Recebido para publicação em: 1 jun. 2020. Aceito para publicação em: 19 jan. 2021. 